\title{
PENERAPAN METODE QOS (QUALITY OF SERVICE) UNTUK MENGANALISA KUALITAS KINERJA JARINGAN WIRELESS
}

\author{
Iman Nurrobi ${ }^{1}$, Kusnadi $^{2}$, Rinaldi Adam ${ }^{3}$ \\ Universitas Catur Insan Cendekia \\ Jl. Kesambi 202, Kota Cirebon, Jawa Barat Tlp : (0231) 220250 \\ e-mail : imannurrobi95@gmail.com ${ }^{1}$, kusnadi@ cic.ac.id ${ }^{2}$, rinaldi.adam@cic.ac.id ${ }^{3}$
}

\begin{abstract}
ABSTRAK
Untuk mengetahui seberapa besar kinerja (performance) jaringan WLAN (Wireless Local Area Netwwork) antara setiap ruangan yang terpasang jaringan wireless, maka harus dilakukan sebuah analisis pengukuran parameter kinerja jaringan. QOS (Quality of Services) adalah kemampuan dalam menjamin pengiriman arus data penting atau dengan kata lain kumpulan dari berbagai kriteria kemampuan yang menentukan tingkat kepuasan penggunaan suatu Jaringan. Analisis kinerja jaringan WLAN (Wireless Local Area Netwwork) menekankan pada proses monitoring dan pengukuran parameter jaringan pada infrastruktur jaringan seperti kecepatan akses dan kapasitas transmisi, dari titik pengirim ke titik penerima yang menjadi tujuan, parameter yang digunakan bandwidth, delay, dan packet loss.
\end{abstract}

Kata Kunci : WLAN, QoS, Througput, Delay, Packet Loss.

\section{ABSTRACT}

To find out how much performance (Wireless Local Area Netwwork) network performance between each room that is installed with a wireless network, an analysis of network performance parameter measurements must be performed. QOS (Quality of Services) is the ability to guarantee the delivery of important data flows or in other words a collection of various capability criteria that determine the level of satisfaction of using a network. Analysis of WLAN (Wireless Local Area Netwwork) network performance emphasizes the process of monitoring and measuring network parameters in network infrastructure such as access speed and transmission capacity, from the sending point to the receiving point to the destination, the parameters used for bandwidth, delay, and packet loss.

Keywords: WLAN, QoS, Througput, Delay, Packet Loss.

\section{PENDAhuluan}

\subsection{Latar Belakang}

Teknologi informasi khususnya pada jaringan komputer pada saat ini telah menjadi salah satu hal yang mendasar dalam semua segi. Sulit dibayangkan pada era teknologi informasi pada saat sekarang tanpa menggunakan teknologi jaringan komputer. Hal ini dapat dilihat dari penggunaan jaringan komputer baik itu secara umum maupun pribadi, banyaknya kebutuhan akan akses dan komunikasi maka kinerja jaringan harus berada pada kondisi yang baik, maka operator jaringan dan internet service provider (ISP) harus dapat memecahkan masalah utama yaitu menyediakan kinerja layanan yang bagus untuk dapat memberikan layanan yang nyaman kepada pengguna. SMK Korpri Majalengka adalah Sekolah Menengah Kejuruan yang didirikan Tanggal 21 Juli 1998 memiliki tujuan menyiapkan siswa menjadi tenaga kerja tingkat menengah untuk mengisi kebutuhan Dunia Usaha dan Industri pada masa sekarang dan masa yang akan datang. Oleh sebab itu pembenahan dalam hal infrastruktur dan menajemen selalu dilakukan demi tercapainya tujuan tersebut.

Pada saat sekarang ini SMK Korpri Majalengka menggunakan jaringan internet dengan provider Telkom speedy dengan jumlah bandwidth $100 \mathrm{MB}$ (Mega Byte). Saat ini fasilitas internet terkoneksi dibagi menjadi 3 jalur yaitu $10 \mathrm{Mb}$ yaitu ke ruangan kepala sekolah, tata usaha, $70 \mathrm{MB}$ ruangan praktek/lab siswa, lalu sisanya 20 MB untuk khusus wifi, seperti bengkel, ruang kesiswaan, ruang BKK dan 5 ruangan lainnya, 
karena yang diteliti adalah jaringan wireless yang pada waktu tertentu kestabilannya dapat berubah-ubah maka penulis akan melakukan pengukuran Quality of Service (QoS) dimana $Q o S$ itu bisa mengukur bandwith, delay dan paket loss dengan standarisasi dari TIPHON[5]. Dari setiap parameter yang diukur penulis mendapatkan penyebab terjadinya masalah yang mempengaruhi nilai parameter yaitu besarnya trafik jaringan melebihi dari kapasitas bandwidth seperti banyak siswa yang membuka aplikasi seperti youtube, facebook dan twitter dikarenakan tidak adanya pemblokiran situs-situs non akademis dari pihak sekolah yang juga membuat bandwidth menjadi padat dan juga node yang bekerja melebihi kapasitas buffer dikarenakan memory yang terbatas pada node sehingga menyebabkan delay, packet loss dan bandwidth jaringan menjadi tidak stabil, ditambah lagi belum adanya manajemen bandwidth yang teratur dari setiap user. Pada saat ini SMK Korpri Majalengka memiliki beberapa perangkat jaringan seperti 250 lebih komputer yang tersedia, 10 Access Point, 9 Switch dan 3 Modem.

Dari permasalahan tersebut pembagian bandwith $100 \mathrm{MB}$ untuk 3 ruangan terjadi masalah yaitu kestabilan jaringan untuk wifi di SMK tersebut belum melakukan pengukuran kualitas layanan jaringan wireless. Maka dari itu penulis tertarik untuk melakukan pengukuran QOS (Quality of Service) untuk mengetahui seberapa nilai parameter pada SMK Korpri Majalengka harus dilakukan sebuah analisis pengukuran kualitas jaringan wireless.

\subsection{Identifkasi Masalah}

Berdasarkan latar belakang masalah diatas, maka penulis menguraikan identifikasi permasalahan sebagai berikut :

1. Bagaimana cara mengetahui pembagian bandwidth untuk jaringan wifi yang masih kurang?

2. Bagaimana mengukur bandwidth, delay dan packet loss di jaringan wifi?

3. Bagaimana cara tahapan menganalisa jaringan wifi menggunakan metode QOS (Quality Of Service)?

\subsection{Batasan Masalah}

Penulis membatasi permasalahan dalam penulisan ini agar pembahasan tidak menyimpang dari tujuan, maka dilakukan pembatasan masalah sebagai berikut :

1. Melakukan pengkuran menggunakan metode QOS (Quality Of Service) yaitu bandwidth, delay, dan packet loss.

2. Mengukur dan menganalisis kinerja jaringan wifi menggunakan QOS (Quality Of Service).

3. Pengukuran menggunakan standarisasi dari TIPHONE.

\subsection{Tujuan Penelitian}

Adapun tujuan dibuatnya prototype ini adalah sebagai berikut :

1. Untuk mengetahui dan menentukan nilai $Q o S$ (Quality of Service) dari jaringan wifi

2. Untuk mengetahui apa yang dibutuhkan dalam menunjang performansi jaringan.

\section{KAJIAN PUSTAKA}

\subsection{Analisis}

Analisis data adalah proses mengatur urutan data, mengorganisasikanya ke dalam suatu pola, kategori, dan satuan uraian dasar [1]. Sedangkan menurut [1] mendefinisikan analisis data sebagai proses yang merinci usaha secara formal untuk menemukan tema dan merumuskan hipotesis (ide) seperti yang disarankan dan sebagai usaha untuk memberikan bantuan dan tema pada hipotesis. Jika dikaji, pada dasarnya definisi pertama lebih menitik beratkan pengorganisasian data sedangkan yang ke dua lebih menekankan maksud dan tujuan analisis data. Dengan demikian definisi tersebut dapat disintesiskan menjadi, Analisis data adalah proses mengorganisasikan dan mengurutkan data ke dalam pola, kategori dan satuan uraian dasar sehingga dapat ditemukan tema dan dapat dirumuskan hipotesis kerja seperti yang didasarkan oleh data. Dari uraian tersebut di atas dapatlah kita menarik garis bawah analisis data bermaksud pertama-tama mengorganisasikan data. Data yang terkumpul banyak sekali dan terdiri dari catatan lapangan dan komentar peneliti, gambar, foto, dokumen, berupa laporan, biografi, artikel, dan sebagainya. Pekerjaan analisis data dalam hal ini ialah mengatur, mengurutkan, mengelompokkan, memberikan kode, dan mengategorikannya. Pengorganisasian dan pengelolaan data tersebut bertujuan menemukan tema dan hipotesis kerja yang akhirnya diangkat menjadi teori substantif.

\subsection{Quality of Services (QoS)}

QoS yaitu sebuah tata cara untuk memberikan kemampuan kepada seorang admin jaringan komputer untuk melakukan kegiatan pengelolaab bandwidth, loss, delay, jitter dan congestion dari throughput dalam 
sebuah jaringan [3]. Qos memiliki 3 tingkatan yang sering digunakan yaitu antara lain Best-effort service, Integrated service dan Differentiated service [4]. Best-effort service yaitu sebuah model service yang mana sebuah aplikasi pada setiap kali mengirimkan data diharuskan tanpa harus meminta izin kepada jaringan komputer. Integrated service yaitu sebuah service yang berfungsi serta dapat menampung beberapa persyaratan dari $Q o S$. Dalam service ini sebuah aplikasi meminta jenis service tertentu dahulu sebelum mengirimkan data dan aplikasi ini diharapkan dapat mengirimkan datanya hanya setelah mendapat konfirmasi terlebih dahulu dari jaringan. Differentiated service yaitu sebuah service yang dapat memenuhi persyaratan dari $Q o S$ yang berbeda, tapi tidak seperti pada Integrated service pada jenis ini tidak secara eksplisit memberi isyarat router sebelum mengirimkan datanya.

\subsubsection{Parameter QoS}

Parameter-parameter $Q o S$ antara lain Bandwidth, Delay dan Packet Loss. Bandwidth merupakan suatu ukuran waktu menggunakan jalur internet yang spesifik dalam kegiatan mengunduh suatu file. Delay yaitu lamanya waktu yang dibutuhkan oleh sebuah data untuk sampai ke tempat tujuan data. Suatu Delay akan menentukan langkah apa yang akan kita ambil ketika kita mengatur suatu jaringan. Ketika Delay bernilai besar akan dapat diketahui bahwa jaringan dalam keadaan sibuk atau kemunkinan lain kapasitas dari jaringan tersebut yang berukuran kecil. Menurut versi TIPHON [5], standarisasi nilai delay sebagai berikut.

Tabel 1. Standarisasi Delay versi TIPHON

\begin{tabular}{|l|c|}
\hline \multicolumn{1}{|c|}{ Kategori Latency } & Besar Delay \\
\hline Sangat bagus & $<150 \mathrm{~ms}$ \\
\hline Bagus & $150 \mathrm{~s} / \mathrm{d} 300 \mathrm{~ms}$ \\
\hline Sedang & $300 \mathrm{~s} / \mathrm{d} 450 \mathrm{~ms}$ \\
\hline Jelek & $>450 \mathrm{~ms}$ \\
\hline
\end{tabular}

Packet Loss yaitu banyaknya paket yang gagal mencapai tempat tujuan. Packet Loss bernilai besar bisa diperkirakan sedang terjadi jaringan sibuk atau sedang terjadi overload. Packet Loss mempengaruhi kinerja jaringan secara langsung.

Tabel 2. Standarisasi Packet Loss versi TIPHON

\begin{tabular}{|l|c|}
\hline \multicolumn{1}{|c|}{ Kategori Degradasi } & Packet Loss \\
\hline Sangat bagus & 0 \\
\hline Bagus & $3 \%$ \\
\hline Sedang & $15 \%$ \\
\hline Jelek & $25 \%$ \\
\hline
\end{tabular}

\section{ANALISA JARINGAN DAN PERANCANGAN SISTEM}

\subsection{Analisis}

Analisis merupakan proses penguraian konsep ke dalam bagian-bagian yang lebih sederhana, sehingga struktur logisnya menjadi jelas. Analisis merupakan metode untuk menguji, menilai, dan memahami sistem pemikiran yang kompleks dengan memecahnya ke dalam unsur-unsur yang lebih sederhana sehingga hubungan antar unsur-unsur itu menjadi jelas.

\subsubsection{Analisis Tempat}

Di pembahasan analisi tempat, saya akan menjelaskan apa saja yang tersedia di SMK Korpri Majalengka, seperti berapa gedung yang ada, berapa ruangan yang tersedia, berapa banyak penggunanya siswa dan guru.

\section{Gedung}

Di tabel 3.1 yang saya akan bahas adalah ada berapa gedung di SMK Korpri dan di masing-masing gedung terdiri dari beberapa ruangan dan juga ketersedian jaringan internet di masing-masing gedung. 
Tabel 3. Gedung

\begin{tabular}{|c|l|}
\hline Nama & \multicolumn{1}{|c|}{ Ruangan } \\
\hline Gedung A & $\begin{array}{l}\text { Ruang kelas, Ruang Kepala Sekolah, } \\
\text { Ruang Tata Usaha, Lab }\end{array}$ \\
\hline Gedung B & $\begin{array}{l}\text { Bengkel, Studio Musik, Perpustakaan, } \\
\text { Ruang LSP, BKK, Kesiswaan }\end{array}$ \\
\hline
\end{tabular}

SMK Korpri Majalengka terdiri dari 2 gedung yaitu ada gedung A dan Gedung B. Di gedung A terdiri dari 2 lantai dan ada ruangan untuk ruang kelas, ruang kepala sekolah, ruang tata usaha, lab. Di gedung A sendiri mempunyai jaringan internet seperti kabel dan dan non kabel (wireless) tapi masing-masing ruangan ada yang mempunyai 2 jaringan intenet bahkan ada yang tidak mempunyai jaringan internet seperti lab hanya mempunyai jaringan kabel, untuk ruang tata usaha dan ruang kepala sekolah mempunyai 2 jaringan kabel dan non kabel (wireless) sedangkan untuk ruang kelas tidak mempunyai akses internet sama sekali. Gedung B sendiri memiliki ruangan seperti Bengkel, Studio Musik, Perpustakaan, Ruang LSP, BKK dan Kesiswaan, dan khusus di gedung $\mathrm{B}$ atau dibagian belakang hanya memiliki jaringan non kabel (wireless) disetiap ruangannya.

\section{Ruangan}

Pada tabel 4 adalah ruangan-rungan seperti Ruang kelas, Ruang Kepala Sekolah, Ruang Tata Usaha, Lab, Bengkel, Studio Musik, Perpustakaan, Ruang LSP, BKK, Kesiswaan

Tabel 4. Ruangan

\begin{tabular}{|l|c|}
\hline \multicolumn{1}{|c|}{ Nama } & Jumlah \\
\hline Ruang Kelas & 37 \\
\hline Ruang Tata Usaha & 1 \\
\hline Lab Komputer & 7 \\
\hline Bengkel & 1 \\
\hline Perpustakaan & 1 \\
\hline Ruang Kepala Sekolah & 1 \\
\hline Studio Musik & 1 \\
\hline Ruang LSP & 1 \\
\hline Ruang BKK & 1 \\
\hline Ruang Kesiswaan & \\
\hline
\end{tabular}

Ruang kelas terdiri dari 37 ruangan untuk siswa jurusan TKJ (Teknik Komputer Jaringan), TP (Teknik Pemesinan), dan TKR (Teknik Kendaraan Ringan) dan disetiap kelas tidak mempunyai jaringan internet. Untuk lab komputer mereka mempunyai 7 lab, dimana masing-masing lab memiliki sekitar 36 komputer, tersedia jaringan internet seperti jaringan kabel saja. Untuk ruang tata usaha dan ruang kepala sekolah memiliki 1 ruangan dan diruangannya memiliki 2 akses internet sepeti jaringan kabel dan non kabel (wireless). Untuk bengkel terdiri dari 3 ruangan, yang dimana dimasing-masing bengkel mempunyai jaringan non kabel (wireless) nya sendiri dan sisanya seperti Perpustakaan, Studio Musik, Ruang LSP, Ruang BKK, Ruang Kesiswaan memiliki masing-masing 1 ruangan dan memiliki jaringan non kabel (wireless) nya masing-masing. 


\section{Pengguna}

Tabel 5 adalah tabel pengguna, yang dimaksud pengguna disini adalah yang ada diruang lingkup sekolah tersebut seperti guru/staff dan siswa.

Tabel 5. Pengguna

\begin{tabular}{|l|c|}
\hline \multicolumn{1}{|c|}{ Nama } & Jumlah \\
\hline Siswa & 1500 \\
\hline Guru/staff & 30 \\
\hline
\end{tabular}

SMK Korpri memiliki cukup banyak siswa dan guru/staff yang ada saat ini. Untuk siswa tahun sekarang mereka memiliki sekitar 1500 siswa dengan laki-laki terdiri sekitar 1300 orang sedangkan perempuan hanya 200 orang, tentu lebih dominan ke siswa laki-laki. Untuk guru/staff sendiri sekitar 30 orang dikarenakan sering banyaknya guru/staff yang keluar atau masuk dan terkadang tidak menentu.

\section{Kondisi Jaringan}

Untuk kondisi jaringan di SMK Korpri saat ini, mereka menggunakan ISP dengan provider Telkom dan produknya yaitu Indihome dengan bandwith yang tersedia $100 \mathrm{MB}$ (Mega Byte) yang dibagi menajdi 3 jalur, yang dimana setiap jalur mempunyai bandwithnya sendiri, seperti untuk lab tersedia 70mbps lalu untuk ruang tata usaha dan ruang kepala sekolah tersedai 10mbps dan terakhir untuk ruang belakang di khusus kan untuk wifi tersedia 20mbps.

\subsubsection{Perangkat Jaringan}

Pada perangkat jaringan ini dijelaskan mengenai perangkat apa saja yang tersedia dan juga produk yang dipakai di SMK Korpri Majalengka:

\section{Perangkat Tersedia}

Dibagian perangkat ini saya memberi informasi ketersediaan perangkat keras (hardware) yang dimiliki SMK Korpri Majalengka seperti ada berapa komputer yang tersedia, router, access point, switch dan modem.

Tabel 6. Perangkat Tersedia

\begin{tabular}{|l|c|}
\hline \multicolumn{1}{|c|}{ Nama } & Jumlah \\
\hline Modem & 3 \\
\cline { 2 - 2 } Switch & 9 \\
\hline Access Point & 10 \\
\hline
\end{tabular}

Tabel 6 menginformasikan ketersediaan perangkat jaringan yang ada di SMK Korpri Majalengka seperti komputer yang tersedia di setiap ruangan seperti di lab, ruang guru, bengkel dan lainya. Lalu tambahan perangkat agar berjalannya sebuah jaringan yaitu, access point, switch dan modem.

\section{Nama Perangkat}

Dibagian nama perangkat ini saya ingin memberi informasi tentang apa saja merek perangkat keras yang digunkan di SMK Korpri majalengka seperti access point, switch, modem dan kabel yang digunakan.

Tabel 7.Nama Perangkat

\begin{tabular}{|l|c|}
\hline \multicolumn{1}{|c|}{ Nama } & Nama Merk Perangkat \\
\hline Modem & Huawei HG8245H \\
\hline \multirow{2}{*}{ Switch } & TP-LINK SG1008D 8 PORT \\
\cline { 2 - 2 } & TP-LINK SG1016D 16 PORT \\
\hline \multirow{2}{*}{ Access Point } & ASUS-N300 \\
\cline { 2 - 2 } & TP-LINK WA801ND \\
\hline Kabel & UTP CAT 5e \\
\hline
\end{tabular}




\section{Media Jaringan}

SMK Korpri Majalengka mempunyai dua jaringan internet yaitu menggunkan kabel dan non kabel (wireless). Untuk jaringan kabel sendiri mereka menggunkan kabel UTP (Unshielded Twisted Pair) Cat 5E, dari ruang pusat disebarkan kesetiap ruangan yang membutuhkan jaringan non kabel, jaringan non kabel (wireless) yaitu TELKOM dan produknya INDIHOME.

\subsubsection{Topologi Jaringan}

Berikut adalah sedikit gambaran yang sudah coba saya buat yaitu ada topologi jaringan yang ada di SMK Korpri Majalengka dengan menggunakan kelas c dan mempunyai 3 jalur akses internet :

\section{Topologi Jaringan LAB}

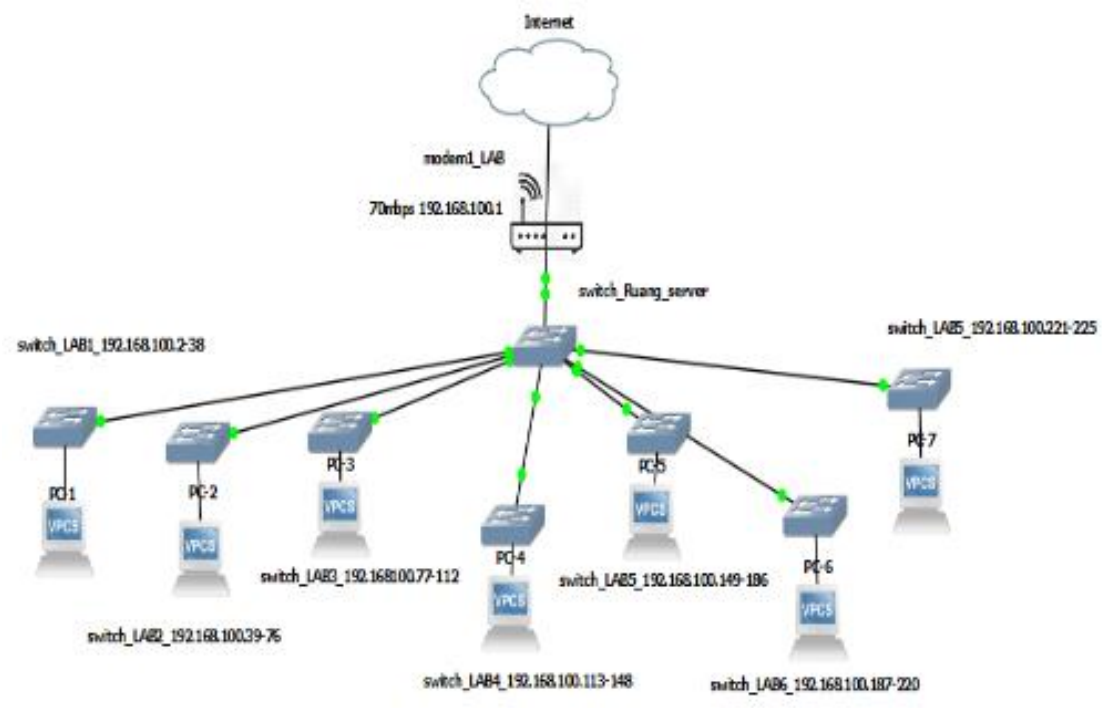

Gambar 1. Topologi Jaringan LAB

Topologi Jaringan LAB dengan 1 modem yang tersebar ke 7 lab, dan masing-masing lab mempunyai 36 komputer dan 1 operator dengan ketersedian bandwith $70 \mathrm{mbps}$, dari ISP yang terhubung ke modem dengan ip 192.168.100.1 lalu dari modem terhubung ke switch lalu diteruskan ke switch antar lab untuk mendapatkan ip 192.168.100.2-38 sampai lab terakhir dengan ip 192.168.100.221-255.

\section{Topologi Jaringan Ruang TU dan Ruang Kepala Sekolah}

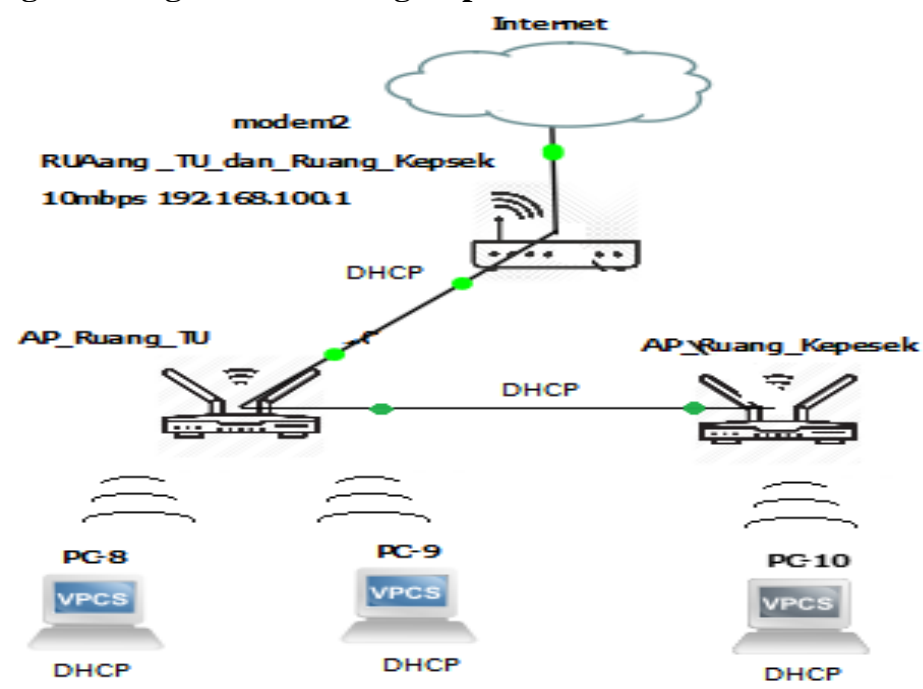

Gambar 2. Topologi Jaringan Ruang TU dan Ruang Kepala Sekolah 
Pada gambar 2 Menggambarkan jalur internet untuk ruang tata usaha dan ruang kepala sekolah dimana modem kapasitas bandtwith 10 mbps dengan ip 192.168.100.1 di teruskan ek access point ruang tata usaha dengan mendapatkan ip 192.168.100.2-40 kemudian diteruskan ke ruang kepala sekolah dengan ip dhcp dan disetiap ruangan seperti ruang tata usaha dan ruang kepala sekolah memiliki komputer dengan memakai wireless dongle untuk wifi, agar setiap komputer terhubung ke access point.

\section{Topologi Jaringan Ruang Belakang}

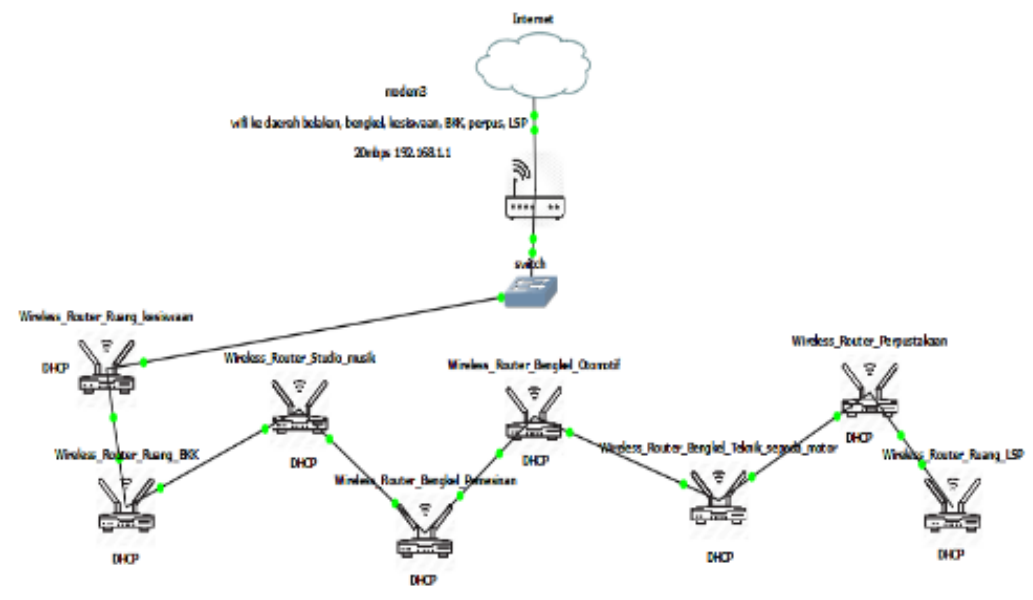

Gambar 3. Topologi Jaringan Ruang Belakang

Pada gambar 3 yaitu topologi khusus wifi yang terhubung dengan ruang belakang dimana ada ruang kesiswaan, BKK, studio musik, perpustakaan, LSP, bengkel pemesinan, otomotif, sepeda motor. Untuk bandwith tersedia 20 mbps, modem dengan ip 192.168.1.1 yang terhubung ke switch lalu terhubung dan diteruskan ke wireless router yang ada di setiap ruangan dan masing-masing wireless router menggunakan DHCP.

\subsection{Perancangan}

\subsubsection{Tahapan Analisis QOS}

Tahapan Perancangan QOS ini akan dibuat analisasi jaringan internet wifi SMK Korpri Majalengka yaitu menganalisa bandwith, delay dan packet loss, yang dianalisa yaitu jaringan wifi di 8 titik yang tersedia jaringan wifi, disetiap ruangan saya akan mencoba 2 tahapan pengujian jaringan dengan kisaran waktu sekitar 15-30 menit, yang pertama saya akan lakukan adalah mencoba menguji jaringan tanpa adanya siswa/user yang terkoneksi dengan jaringan wifi, disaat itu apakah jaringan masih stabil atau tidak. Kedua saya akan mencoba menguji jaringan dengan banyak user yang terkoneksi dengan jaringan wifi, ketika ada user yang menggunakan wifi, apakah jaringan masih akan tetap stabil atau tidak. Dari dua pengujian jaringan wifi apakah semua jaringan masih stabil atau salah satunya mengalami penurunan jaringan yang drastis. Berikut contoh tabel pengujian:

\section{Bandwidth}

Proses analisis QOS pada bandwidth dilakukan selama enam hari, didelapan titik yang tersedia jaringan wifi. Proses pengukuran dilakukan pada jam yang sudah ditentukan, yaitu jam 08.00-10.00 dan jam 10:0012.00, dari waktu tersebut hanya dipakai sekitar 30 atau 15 menit, waktu pengukuran akan berbeda-beda. Melalui pengukuran bandwidth menggunakan Axence NetTools dapat dilihat perbandingan nilai bandwitdh antara jam-jam tersebut:

Tabel 8. Contoh Nilai Bandwidth

\begin{tabular}{|c|c|c|c|c|c|}
\hline \multirow{2}{*}{ Hari } & \multirow{2}{*}{ Ruangan } & \multirow{2}{*}{ Waktu (WIB) } & \multicolumn{3}{|c|}{ Bandwitdh } \\
\cline { 4 - 6 } & & & Min & Maks & Rata-Rata \\
\hline Senin & Ruangan A & $10.00-12.00$ & & & \\
\hline Selasa & Ruangan B & $10.00-12.00$ & & & \\
\cline { 2 - 6 } & &
\end{tabular}




\begin{tabular}{|l|c|c|l|l|l|}
\hline Rabu & Ruangan C & $10.00-12.00$ & & & \\
\hline Kamis & Ruangan D & $10.00-12.00$ & & & \\
\hline Jumat & Ruangan E & $10.00-12.00$ & & & \\
\hline Sabtu & Ruangan F & $10.00-12.00$ & & & \\
\hline
\end{tabular}

Berdasarkan tabel yang sudah dibuat, akan tersedia hasil pengukuran bandwidth pada area tertentu yang tersedia jaringan wifi, bandwidth yang diamati selama pengukuran jam 08.00-10.00 dan jam 10.0012.00 yang dilakukan di SMK Korpri Majalengka yang diukur dalam kbps, Bandwidth merupakan jumlah total transfer data yang sukses.

\section{Delay}

Proses kedua dalam analisis QOS yaitu delay, dilakukan selama enam hari, didelapan titik yang tersedia jaringan wifi. Proses pengukuran dilakukan pada jam yang sudah di tentukan, yaitu jam 08.00-10.00 dan jam 10:00-12.00, dari waktu tersebut hanya dipakai sekitar 30 atau 15 menit, waktu pengukuran akan berbedabeda. Melalui pengukuran delay menggunakan Axence NetTools dapat dilihat perbandingan nilai delay antara jam-jam tersebut:

\section{Tabel 9. Contoh Nilai Delay}

\begin{tabular}{|l|l|l|l|l|l|}
\hline \multirow{2}{*}{ Hari } & \multirow{2}{*}{ Ruangan } & \multirow{2}{*}{ Waktu (WIB) } & \multicolumn{3}{|c|}{ Delay } \\
\cline { 4 - 6 } & & & Min & Maks & Rata-Rata \\
\hline Senin & Ruangan A & $10.00-12.00$ & & & \\
\hline Selasa & Ruangan B & $10.00-12.00$ & & & \\
\hline Rabu & Ruangan C & $10.00-12.00$ & & & \\
\hline Kamis & Ruangan D & $10.00-12.00$ & & & \\
\hline Jumat & Ruangan E & $10.00-12.00$ & & & \\
\hline Sabtu & Ruangan F & $10.00-12.00$ & & & \\
\hline
\end{tabular}

Berdasarkan tabel yang sudah dibuat, akan tersedia hasil pengukuran delay pada area tertentu yang tersedia jaringan wifi, delay yang diamati selama pegukuran jam 10.00-11.00 dan jam 13.00-14.00 yang dilakukan pada jam sibuk di SMK Korpri Majalengka. Delay di pengaruhi oleh jarak, media fisik, kongesti atau juga waktu proses yang lama transfer data.

\section{Packet Loss}

Proses ketiga dalam analisis QOS yaitu packet loss, dilakukan selama enam hari, di delapan titik yang tersedia jaringan wifi. Proses pengukuran dilakukan pada jam yang sudah di tentukan, yaitu jam 08.00-10.00 dan jam 10:00-12.00, dari waktu tersebut hanya dipakai sekitar 30 atau 15 menit, waktu pengukuran akan berbeda-beda. Melalui pengukuran packet loss menggunakan Axence NetTools dapat dilihat perbandingan nilai packet loss antara jam-jam tersebut:

Tabel 10. Contoh Nilai Packet Loss

\begin{tabular}{|l|c|c|c|c|c|}
\hline \multirow{2}{*}{ Hari } & \multirow{2}{*}{ Ruangan } & Waktu (WIB) & \multicolumn{3}{|c|}{ Packet } \\
\cline { 4 - 6 } & & & Sent & Lost & Lost\% \\
\hline Senin & Ruangan A & $10.00-12.00$ & & & \\
\hline Selasa & Ruangan B & $10.00-12.00$ & & & \\
\hline Rabu & Ruangan C & $10.00-12.00$ & & & \\
\hline Kamis & Ruangan D & $10.00-12.00$ & & & \\
\hline Jumat & Ruangan E & $10.00-12.00$ & & & \\
\hline Sabtu & Ruangan F & $10.00-12.00$ & & & \\
\hline
\end{tabular}

Berdasarkan tabel yang sudah dibuat, akan tersedia hasil pengukuran delay pada area tertentu yang tersedia jaringan wifi, delay yang diamati selama pegukuran jam 80.00-10.00 dan jam 10.00-12.00 yang dilakukan di SMK Korpri Majalengka. Paket loss yang menggambarkan suatu kondisi yang menunjukkan jumlah total paket loss yang hilang, dapat terjadi karena collision dan congestion pada jaringan. 


\section{Hasil Penelitian}

Untuk mengimplementasikan rencana yang sudah disusun, maka model sistem monitoring $Q o S$ yang digunakan untuk pengukuran parameter megunakan software Axence NetTools pada jaringan WLAN di SMK Korpri Majalengka yaitu bandwidth, delay dan packet loss pada ruangan yang terkoneksi wifi.

\subsection{Hasil Analisis QOS}

1. Ruang Perpustakaan

\section{a. Bandwidth}

Dalam proses pengukuran Bandwidth pada area ini dilakukan selama empat hari, yang dimulai pada hari Senin sampai Kamis. Proses pengukurannya dilakukan pada jam sibuk dan kedaan sedang tidak sibuk, yaitu dengan range antara jam 08:00-10:00 dan 10:00-12.00. Melalui pengukuran bandwidth menggunakan Axence NetTools dapat dilihat perbandingan nilai bandwitdh antara dua tahapan yaitu sebagai berikut. Dari hasil pengukuran bandwidth didapatlah hasil sebagai berikut:

Tabel 11. Hasil Bandwidth Perpustakaan

\begin{tabular}{|c|c|c|c|c|c|}
\hline \multirow{2}{*}{ Hari } & Ruangan & \multirow{2}{*}{ Waktu (WIB) } & \multicolumn{3}{|c|}{ Bandwidth } \\
\cline { 4 - 6 } & & & Min & Maks & Rata-Rata \\
\hline Senin & Perpustakaan & $10.00-12.00$ & 9.920 & 493.360 & 43.264 \\
\hline
\end{tabular}

Berdasarkan tabel dan gambar di atas didapatlah hasil pengukuran bandwidth diruangan perpustakaan dan kesiswaan, bandwidth yang diamati selama pegukuran jam 08.00-10.00 dan jam 10.00-12.00. Persamaan sangat terlihat pada dua waktu tersebut, di perpustakaan saja pada saat jam istirahat dan jam masuk terlihat sangat rendah sekali untuk kecepatan bandwidth.

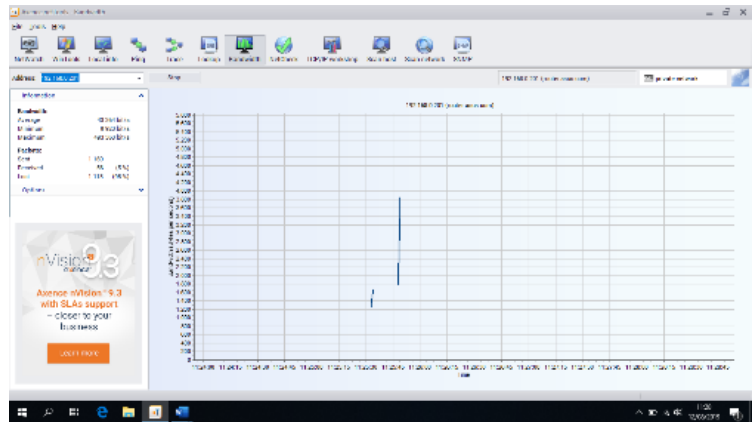

Gambar 4. Hasil Bandwidth Perpustakan pada Jam Istirahat

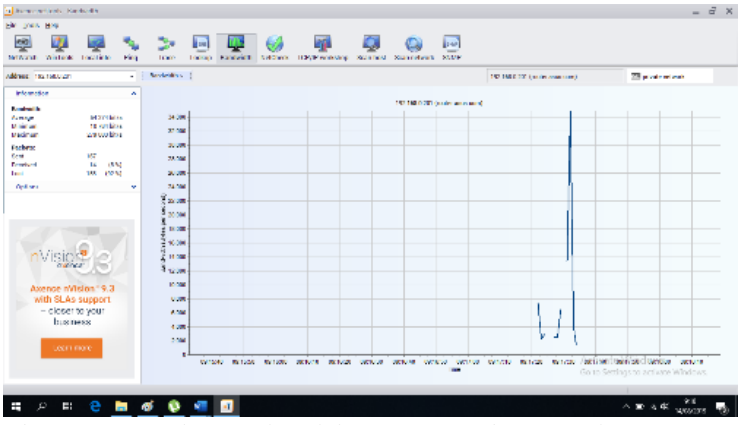

Gambar 5. Hasil Bandwidth Perpustakan pada Jam Masuk

\section{b. Delay}

Delay dapat dipengaruhi oleh jarak, media fisik atau juga proses waktu yang lama dalam jaringan WLAN. Sebagai standarisasi yang digunakan dalam pengukuran nilai delay, maka besarnya delay dapat diklasifikasikan sebagai kategori latensi sangat bagus jika <150 ms, bagus jika $150 \mathrm{~ms}$ sampai dengan 300 $m s$, sedang jika $300 \mathrm{~ms}$ sampai dengan $450 \mathrm{~ms}$ dan jelek jika <450 $\mathrm{ms}$. Dapatlah nilai rata-rata response time delay minimum dan maksimum dalam milise cond $(\mathrm{ms})$ yaitu sebagai berikut: 
Tabel 12. Hasil Delay Perpustakaan

\begin{tabular}{|c|c|c|c|c|c|}
\hline \multirow{2}{*}{ Hari } & Ruangan & \multirow{2}{*}{ Waktu (WIB) } & \multicolumn{3}{|c|}{ Delay } \\
\cline { 4 - 6 } & & & Min & Maks & Rata-Rata \\
\hline Senin & Perpustakaan & $10.00-12.00$ & 2 & 992 & 449 \\
\hline
\end{tabular}

Dari hasil tabel di atas dan berdasarkan nilai besar delay sesuai dengan tabel versi TIPHON di ruangan perpustakaan dan kesiswaan, maka kategori delay untuk setiap hari yang dilakukan pada jam istirahat dan jam masuk antara jam 09.00-10.00 dan jam 10.00-12.00 Delay di pengaruhi oleh jarak, media fisik, kongesti atau juga waktu proses yang lama transfer data.

\section{c. Packet Loss}

Berdasarkan hasil pengukuran terhadap skema perangkat jaringan WLAN di SMK Korpri Majalengka didapat nilai packet loss dalam persentase (\%) sebagai berikut:

Tabel 13. Hasil Packet Loss Perpustakaan

\begin{tabular}{|c|c|c|c|c|c|}
\hline \multirow{2}{*}{ Hari } & Ruangan & \multirow{2}{*}{ Waktu (WIB) } & \multicolumn{3}{|c|}{ Pacekt } \\
\cline { 4 - 6 } & & & Sent & Lost & Lost\% \\
\hline Senin & Perpustakaan & $10.00-12.00$ & 1163 & 446 & 38 \\
\hline
\end{tabular}

Dari tabel di atas dan berdasarkan nilai packet loss sesuai dengan versi TIPHON sebagai standarisasi, di ruangan perpustakaan dan kesiswaan untuk kategori degredasi packet loss sangat bagus jika $0 \%$, bagus jika 3\%, sedang jika 15\% dan jelek jika 25\%, dari hasil di atas paket loss untuk perpustakaan melebihi dari $25 \%$ maka itu jelek sekali, karena suatu parameter yang menggambarkan suatu kondisi yang menunjukkan jumlah total paket loss yang hilang, dapat terjadi karena collision dan congestion pada jaringan Wireless LAN SMK Korpri Majalengka.

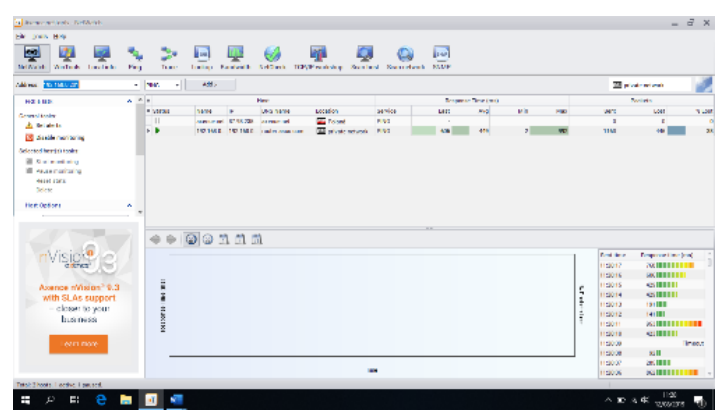

Gambar 6. Hasil Delay dan Packet Loss Perpustakaan pada Jam Istirahat

\section{Ruang Kesiswaan}

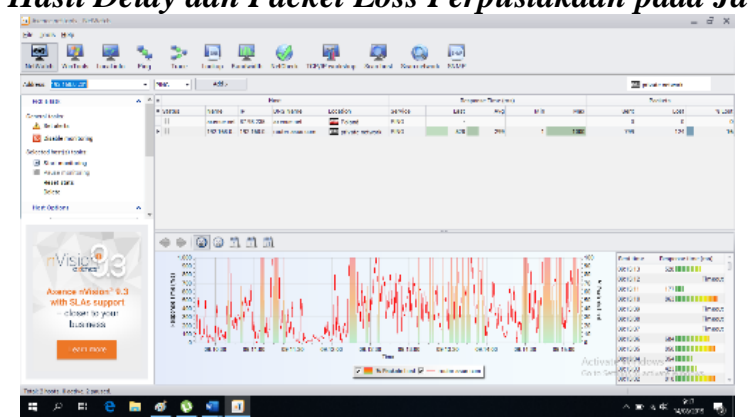

Gambar 7. Hasil Delay dan Packet Loss Perpustakaan pada Jam Masuk

\section{a. Bandwidth}

Dari hasil pengukuran bandwidth melalui monitoring WLAN di Ruang Kesiswaan yang dilakukan pada jam istirahat dan jam masuk yaitu antara pukul 08.00-10.00 dan 10.00-12.00 menggunakan Sofeware monitoring Axence NetTools didapatlah hasil seperti tabel dibawah ini:

Tabel 14. Hasil Bandwidth Kesiswaan

\begin{tabular}{|c|c|c|c|c|c|}
\hline \multirow{2}{*}{ Hari } & Ruangan & \multirow{2}{*}{ Waktu (WIB) } & \multicolumn{3}{|c|}{ Bandwidth } \\
\cline { 4 - 6 } & & & Min & Maks & Rata-Rata \\
\hline Selasa & Kesiswaan & $10.00-12.00$ & 10.128 & 651.176 & 379.296 \\
\hline
\end{tabular}


Berdasarkan tabel di atas dapat disimpulkan bahwa, hasil pengukuran bandwidth di ruangan kesiswaan dalam 2 tahapan terlihat perbedaan untuk bandwidth saat jam istirahat dan jam masuk. Diamati selama pengukuran analisis SMK Korpri Majalengka.

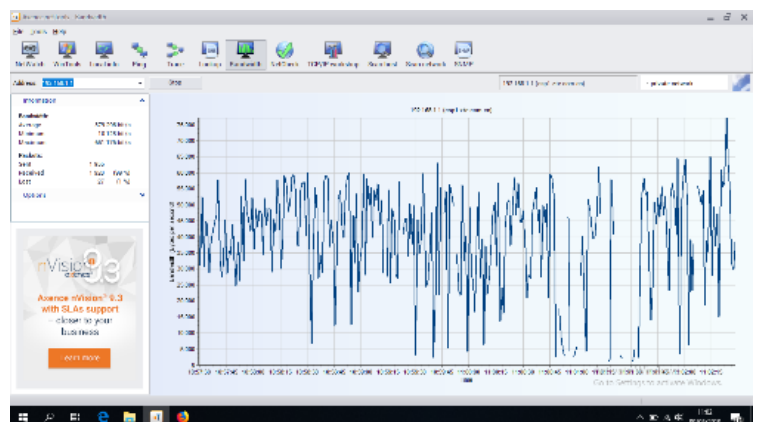

Gambar 8. Hasil Bandwidth Kesiswaan pada Jam Istirahat

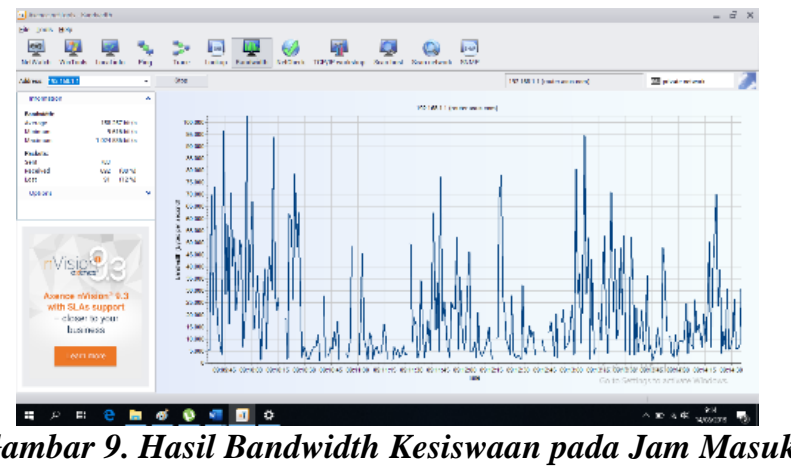

b. Delay

Dari hasil pengukuran nilai delay terhadap skema jaringan WLAN di ruangan Kesiswaan diperoleh nilai delay rata-rata seperti berikut:

Tabel 15. Hasil Delay Kesiswaan

\begin{tabular}{|c|c|c|c|c|c|}
\hline \multirow{2}{*}{ Hari } & Ruangan & \multirow{2}{*}{ Waktu (WIB) } & \multicolumn{3}{|c|}{ Delay } \\
\cline { 4 - 6 } & & & Min & Maks & Rata-Rata \\
\hline Selasa & Kesiswaan & $10.00-12.00$ & 2 & 992 & 449 \\
\hline
\end{tabular}

Dari hasil tabel di atas dan berdasarkan nilai besar delay sesuai dengan tabel versi TIPHON di ruangan kesiswaan, maka kategori delay dilakukan pada jam istirahat dan jam masuk antara jam 09.00-10.00 dan jam 10.00-12.00. Delay di pengaruhi oleh jarak, media fisik, kongesti atau juga waktu proses yang lama transfer data.

\section{c. Packet loss}

Berdasarkan hasil pengukuran terhadap skema perangkat jaringan WLAN di SMK Korpri Majalengka didapat nilai packet loss dalam persentase (\%) sebagai berikut:

Tabel 16. Hasil Packet Loss Kesiswaan

\begin{tabular}{|c|c|c|c|c|c|}
\hline \multirow{2}{*}{ Hari } & \multirow{2}{*}{ Ruangan } & \multirow{2}{*}{ Waktu (WIB) } & \multicolumn{3}{|c|}{ Pacekt } \\
\cline { 4 - 6 } & & & Sent & Lost & Lost\% \\
\hline Selasa & Kesiswaan & $10.00-12.00$ & 682 & 0 & 0 \\
\hline
\end{tabular}

Dari tabel di atas dan berdasarkan nilai packet loss sesuai dengan versi TIPHON sebagai standarisasi, di ruangan kesiswaan untuk kategori degredasi packet loss sangat bagus jika 0\%, bagus jika 3\%, sedang jika $15 \%$ dan jelek jika 25\%, dari hasil di atas paket loss untuk ruang kesiswaan pada jam istirahat $0 \%$ dan jam masuk 3\% sama-sama menandakan sangat bagus untuk nilai packet loss, karena suatu parameter yang 
menggambarkan suatu kondisi yang menunjukkan jumlah total paket loss yang hilang, dapat terjadi karena collision dan congestion pada jaringan Wireless LAN SMK Korpri Majalengka.

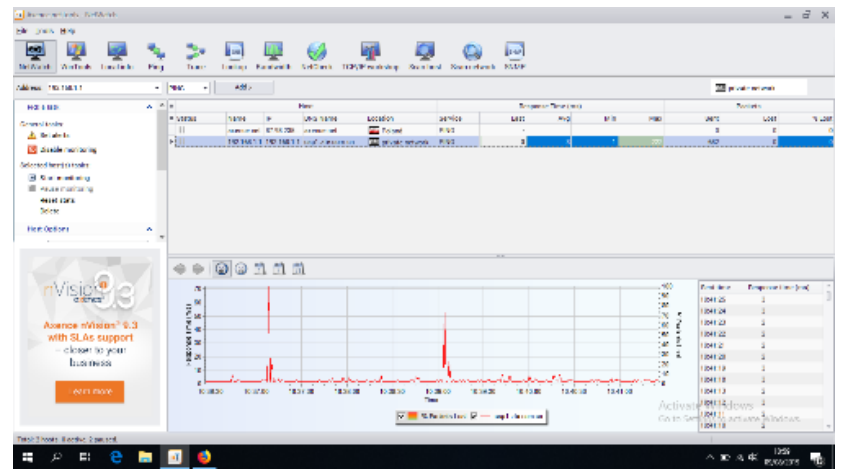

Gambar 10. Hasil Delay dan Packet Loss Kesiswaan Pada Jam Istirahat

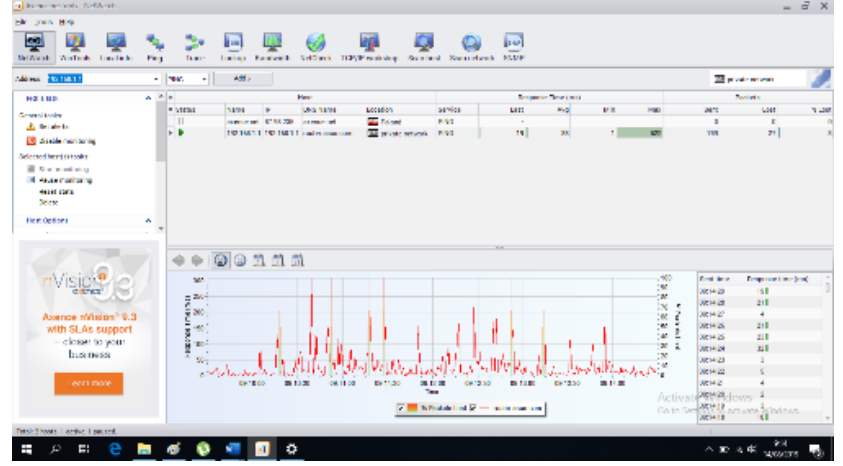

Gambar 11. Hasil Delay dan Packet Loss Kesiswaan Pada Jam Masuk

\section{KESIMPULAN DAN SARAN}

\subsection{Kesimpulan}

Dari hasil analisis kinerja jaringan Wireless LAN SMK Korpri Majalengka, maka dapat disimpulkan sebagai berikut:

1. Telah berhasil diketahui bagaimana cara pembagian bandwidth untuk jaringan wifi di SMK Korpri Majalengka dengan menggunakan metode QoS (Quality of Service).

2. Dengan menggunakan aplikasi Net Tools, sudah tersedia layanan untuk mengukur bandwidth, delay dan packet loss.

3. Dengan menggunakan 2 tahapan yaitu pada saat jam istirahat dan pada saat jam masuk, dapat diketahui jaringan yang mengalami penurunan secara drastis.

\subsection{Saran}

Agar kinerja jaringan WLAN ini dapat berjalan dengan maksimal maka ada beberapa saran antara lain:

1. Perlu pembatasan pemakaian jaringan wifi, seperti di perpustakaan dari semua bandwidth, delay dan packet loss diruangan itulah yang sangat membutuhkan penambahan bandwidth.

2. Penambahan bandwidth untuk jaringan wifi, karena dengan hanya $20 \mathrm{mbps}$ masih kurang untuk siswa yang sangat banyak.

\section{DAFTAR PUSTAKA}

[1] Bogdan dan Taylor, 1975 dalam J. Moleong, Lexy. 1989. Metodologi Penelitian Kualitatif. Bandung: Remadja Karya

[2] Priyambodo, T.K dan Heriadi, D. 2005. Jaringan Wi-Fi. Yogyakarta:Penerbit Andi.

[3] D. Minoli, Hotspot Networking, The McGraw-Hill Companies, 2003

[4] R. S. P, “Analisa Perbandingan QOS VOIP pada jaringan OSPF dan RIP

[5] Tiphon. 1999. Telecommunication and Internet Protocol Harmonization Over Networks (TIPHON) General aspects of Quality of Service (QoS), DTR/TIPHON-05006(cb0010cs.PDF). 